\title{
Review Article \\ Deconstructing GSK-3: The Fine Regulation of Its Activity
}

\author{
Miguel Medina ${ }^{1}$ and Francisco Wandosell ${ }^{2}$ \\ ${ }^{1}$ NOSCIRA S.A., Tres Cantos, 28760 Madrid, Spain \\ ${ }^{2}$ Centro de Biología Molecular "Severo Ochoa," CSIC-UAM-CIBERNED Nicolás Cabrera 1, 28049 Madrid, Spain
}

Correspondence should be addressed to Francisco Wandosell, fwandosell@cbm.uam.es

Received 21 February 2011; Accepted 28 February 2011

Academic Editor: Peter Crouch

Copyright (c) 2011 M. Medina and F. Wandosell. This is an open access article distributed under the Creative Commons Attribution License, which permits unrestricted use, distribution, and reproduction in any medium, provided the original work is properly cited.

\begin{abstract}
Glycogen synthase kinase-3 (GSK-3) unique position in modulating the function of a diverse series of proteins in combination with its association with a wide variety of human disorders has attracted significant attention to the protein both as a therapeutic target and as a means to understand the molecular basis of these disorders. GSK-3 is ubiquitously expressed and, unusually, constitutively active in resting, unstimulated cells. In mammals, GSK- $3 \alpha$ and $\beta$ are each expressed widely at both the RNA and protein levels although some tissues show preferential levels of some of the two proteins. Neither gene appears to be acutely regulated at the transcriptional level, whereas the proteins are controlled posttranslationally, largely through protein-protein interactions or by posttranslational regulation. Control of GSK-3 activity thus occurs by complex mechanisms that are each dependent upon specific signalling pathways. Furthermore, GSK-3 appears to be a cellular nexus, integrating several signalling systems, including several second messengers and a wide selection of cellular stimulants. This paper will focus on the different ways to control GSK-3 activity (phosphorylation, protein complex formation, truncation, subcellular localization, etc.), the main signalling pathways involved in its control, and its pathological deregulation.
\end{abstract}

\section{Introduction}

Glycogen synthase kinase-3 (GSK-3) is a CMGC serine/ threonine protein kinase initially described as one of the kinases that phosphorylates and inhibits glycogen synthase [1]. It is now widely accepted though that GSK-3 plays an important role in various essential physiological processes, such as development, cell cycle, or apoptosis [2]. Apart from glycogen synthase, a plethora of different substrates has been identified in all cellular compartments, that is, metabolic proteins [3], cytoskeletal proteins [4], and transduction [5] and transcription factors [6] (see Table 1).

In neuronal development, GSK-3 has been reported to control morphogenesis and axonal polarity [7], synaptogenesis [8], and survival $[9,10]$. In addition, GSK-3 dysfunction has been associated with brain pathological conditions, such as Alzheimer's disease (AD) $[11,12]$ or prion neurotoxicity [13]. Thus, the deep knowledge of the role of both GSK-3 isoforms in brain metabolism will allow us to understand their contribution to neurodegenerative processes.

GSK-3 unique position in modulating the function of a diverse series of proteins in combination with its association with a wide variety of human disorders has attracted significant attention to the protein both as a therapeutic target and as a means to understand the molecular bases of these disorders. Furthermore, GSK-3 appears to be a cellular nexus, integrating several signalling systems, including numerous second messengers and a wide selection of cellular stimulants.

\section{GSK-3 Structure}

GSK-3 has been highly conserved during evolution, and homolog genes have been identified in virtually every eukaryotic genome investigated, including species, such as Dictyostelium discoideum, Xenopus laevis, or Drosophila melanogaster [14-16]. In mammals, GSK-3 is encoded by two genes known as $g s k-3 \alpha$ and $g s k-3 \beta[17,18]$ encoding GSK$3 \alpha$ (483 aa in humans) and GSK-3 $\beta$ (433 aa) proteins with apparent molecular masses of 51 and $47 \mathrm{kDa}$, respectively. Both isoforms are almost identical (98\%) within their ATP binding pocket but differ at their $\mathrm{N}$ - and C-terminal domains [19]. A neuron-specific splicing isoform ( $\beta 2)$ having an 
TABLE 1: GSK-3 substrates.

\begin{tabular}{lcc}
\hline Metabolic proteins & Structural proteins & $\begin{array}{c}\text { Transcription } \\
\text { factors }\end{array}$ \\
\hline Glycogen synthase & Tau & AP-1 \\
ATP cytrate lyase & MAP1B & $\beta$-catenin \\
PKA & MAP2 & CREB \\
PDH & NCAM & C/EBP \\
Acetyl-CoA & Neurofilaments & Myc \\
carboxylase & CRMP2 & NFkB \\
PP1 & Dynein & NFAT \\
PP2A inhibitor & Dynamin-like & GR \\
PP2A & protein & HSF-1 \\
Cyclin D1 & MBP & Notch \\
eIF2B & APC & p53 \\
NGF receptor & Kinesin light chain & HIF-1 \\
Axin & & \\
APP & & \\
Bax & & \\
VDAC & & \\
Hexokinase & & \\
Presenilin & & \\
LRP5/6 & &
\end{tabular}

GSK3 Selectivity

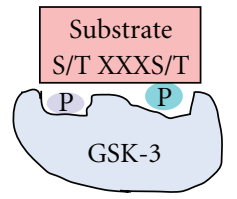

insertion of 13 a a within the substrate-binding domain has also been described [20]. Mammalian GSK-3 $\alpha$ and $\beta$ are each widely expressed although some tissues show preferential levels of some of the two proteins. Neither gene appears to be acutely regulated at the transcriptional level.

Crystallographic studies have revealed the threedimensional structure of GSK-3 $\beta$ [21, 22]. Its overall shape is shared by all kinases, with a small $\mathrm{N}$-terminal lobe mostly consisting of $\beta$-sheets and a large C-terminal lobe essentially formed of $\alpha$-helices [23]. The ATP binding pocket is located between the two lobes and although, is well conserved among kinases [24], it is possible to obtain selective inhibitors by taking advantage of the small differences that exist between the different kinases. Current availability of crystal structures of complexes of GSK-3 $\beta$ with a variety of ligands, together with molecular modelling approaches, provides the necessary clues for enhancing selectivity towards GSK-3 [22].

Some GSK-3 substrates do not require a very specific sequence, but rather a previous (primed) phosphorylation by a priming kinase on a Ser or Thr residue located four aminoacids, C-terminal to the Ser or Thr residue to be modified by GSK-3 (see below for regulation through primed phosphorylation). The crystal structure of human GSK-3 $\beta$ has provided a model for the binding of prephosphorylated substrates to the kinase. According to it, primed Ser/Thr is recognized by a positively charged binding pocket formed by residues Arg96, Arg180, and Lys205 that facilitates the binding of the phosphate group of primed substrates. GSK3 $\beta$ uses the phosphorylated serine or threonine at position +4 of the substrate to align of the two domains for optimal catalytic activity $[21,22]$.

Furthermore, crystal structures of GSK-3 $\beta$ complexes with interacting proteins FRAT/GBP and axin have allowed defining the molecular basis for those interactions, which play critical role in some signalling pathways (see below for regulation through protein complex formation). These studies confirm the partial overlap of the binding sites of axin and FRAT1/GBP predicted from genetic and biochemical studies [2, 25] but reveal significant differences in the detailed interactions and identify key residues mediating the differential interaction with both proteins. This ability of GSK-3 $\beta$ to bind two different proteins with high specificity via the same binding site is mediated by the conformational plasticity of the 285-299 loop, while some residues in this versatile binding site are involved in interactions with both axin and FRAT; others are involved uniquely with one or the other [26].

\section{How Is GSK-3 Activity Controlled?}

As already mentioned above, one of the main characteristics of GSK-3 is that its activity is high in resting, unstimulated cells while regulated by extracellular signals that typically induce a rapid and reversible decrease in enzymatic activity. Glycogen synthase kinase-3 is a dual specificity kinase differentially regulated by tyrosine and serine/threonine phosphorylation [27]. And for many years, it was believed to be a constitutively active kinase; however, it has become apparent that the activity of GSK-3 may be regulated by a variety of means. In fact, control of GSK-3 activity occurs by complex mechanisms that are each dependent upon specific signalling pathways. Thus, the regulatory mechanisms can be classified as follow.

3.1. Regulation by Phosphorylation. The first regulatory mechanism described of GSK-3 activity involved the phosphorylation of specific residues of GSK-3 by other kinases, and more recently through autophosphorylation $[17,28]$.

Four different regions and residues have been described in the GSK-3 molecule. The first one corresponds with a serine residue at positions 21 in GSK- $3 \alpha$ and 9 in GSK-3 $\beta$. It has been clearly established that phosphorylation of serine 21 or 9 correlates with the inhibition of its kinase activity [2931]. Many protein kinases are capable of phosphorylating GSK-3 at this residue, such as Akt, ILK, PKA, and p90Rsk $[32,33]$, and many physiological situations of inhibition of GSK-3 correlate with serine phosphorylation, such as Insulin/IGF1, NGF, or estradiol treatments, not only in neurons [34].

Additionally, two other regulatory sites have been described. One is the threonine 43 , present only in the isoform GSK-3 $\beta$, which may be phosphorylated by Erk [35]. 
Inhibitory pathways

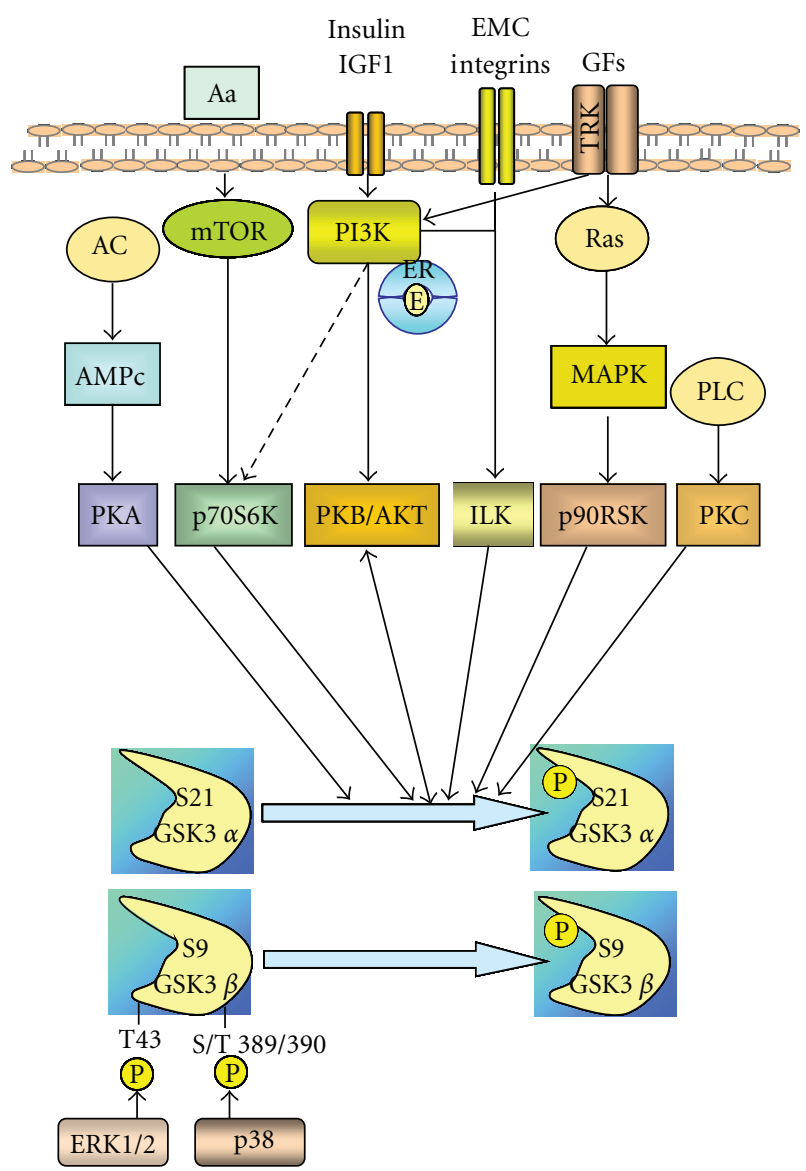

Figure 1

This phosphorylation correlated with GSK-3 inhibition. Second, serine 389 and threonine 390 present in GSK-3 $\beta$ have been shown to be phosphorylated by p38 MAPK [36]. In both cases, the data suggested that this phosphorylation may increase the capacity of Ser-9 to be phosphorylated rather than promote a direct inhibition (see Figure 1).

In contrast, tyrosine phosphorylation present in positions 279 in GSK- $3 \alpha$ or 216 in GSK-3 $\beta$, appears to correlate with an increase of its kinase activity [37]. Different candidates such as Pyk-2 and Fyn kinases have been reported to be able to phosphorylate GSK-3 in vitro on tyrosine. In addition, MEK $1 / 2$ has been showed to have this capacity only in fibroblasts $[38,39]$. This data contrast with those reported in Dictyostelium discoideum where there is compelling evidence indicating that ZAK 1 is responsible for generating tyrosine phosphorylation in GSK-3 [14, 40]. However, no homologue of such kinase has been found in mammals.

More recently, an alternative hypothesis has been proposed for the regulation of GSK-3 tyrosine phosphorylation. This hypothesis suggests that in mammalian systems phosphotyrosine in GSK-3 corresponds to an intramolecular autophosphorylation event and may be regulated by Hsp90 [41]. Molecular dynamics and crystallographic
Activation signaling

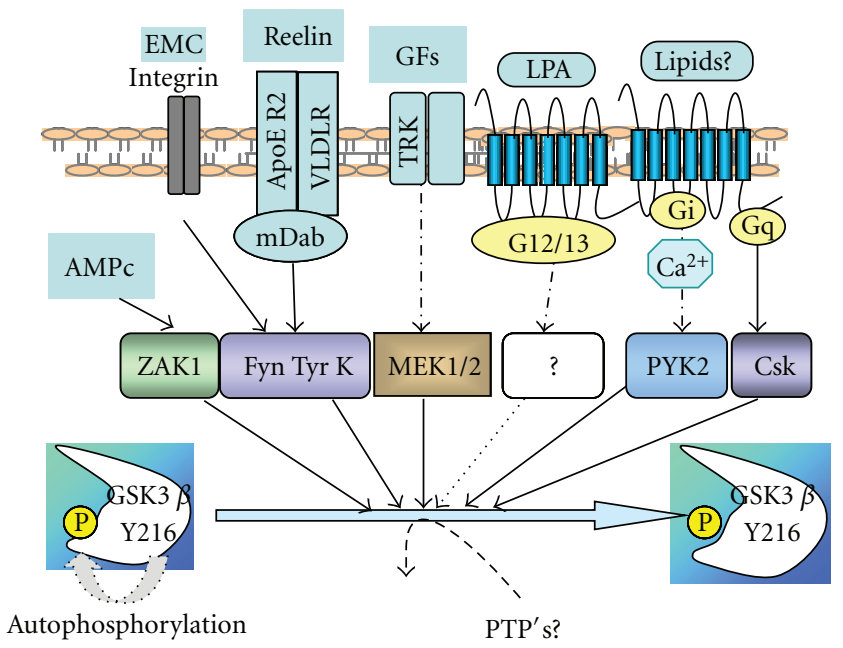

Figure 2

studies clearly suggest that Tyr216 renders the kinase active through interactions with Arg220 and Arg223, stabilizing the activation loop and allowing full substrate accessibility $[42,43]$. However, this hypothesis still lacks a cellular demonstration.

However, our data indicated that not all pharmacological inhibitors of GSK-3 decrease the level of phosphotyrosine. Therefore, lithium chloride inhibits GSK-3 activity, but this inhibition does not alter its pTyr content [44]. Moreover, in neuronal cells, tyrosine phosphorylation of residue 216 or 279 increased following exposure to LPA [37] and even upon exposure of neurons to $\beta$-amyloid or $\operatorname{PrP}[13,45,46]$ in a clear correlation with an increase in GSK-3 activity. In addition, in many neuronal cells, the pharmacological inhibition of tyrosine phosphatases with ortho-vanadate increases the basal level of GSK-3-pTyr [44]. Thus, considering all these data, in addition to this tantalizing autoregulatory system proposed, we hypothesized that some as-yet-unidentified tyrosine kinases and phosphatases may also regulate this kinase (see Figure 2).

3.2. Regulation by Protein Complex Association. One regulatory mechanism that is still not fully understood involves the interaction of the GSK-3 with structural proteins (scaffold proteins). It is well known that GSK-3 contributes to a multiprotein complex formed by axin and adenomatous polyposis coli (APC), among others (for review see, i.e., [47]). This protein complex is the core of canonical Wnt signalling (see below). Indeed, in the absence of ligand, GSK-3 is able to phosphorylate $\beta$-catenin for targeting it for proteasome degradation [48]. More recently, some data suggests that this complex may be specific for GSK- $3 \beta 2$ isoform [49], which opens the possibility of a deeper analysis of "specific functions of GSK-3 isoforms."

Another system of protein-kinase interaction was denoted as GSK-3-binding protein (GBP or FRAT) $[25,50]$. 
Three different FRATs have been cloned and characterized; however, their mechanism of action is not well understood. FRAT1 appears to act as an inhibitory system [51], whereas FRAT2 appears to preferentially increase GSK-3-mediated phosphorylation in some residues [52]. Surprisingly, recent data demonstrated that FRAT is dispensable because the triple FRAT-knockout mouse lacks any major defect in brain development [53]. All these data indicated that the precise role of FRAT in GSK-3 regulation is still to be defined.

Using the binding site on GSK-3 for FRAT/GBP, a GSK3 -interacting protein symbolized by GSKIP has been cloned and characterized. GSKIP can block phosphorylation of different substrates and functions as a negative regulator of GSK-3 beta [54].

3.3. Regulation by Priming/Substrate Specificity. As previously mentioned, the specificity of many kinases is governed by a consensus sequence of aminoacids sequence. However, as almost general rule, GSK-3 substrates do not require a very specific sequence, but a previous (primed) phosphorylation residue modified by a priming kinase located four aminoacids, C-terminal, to the Ser or Thr residue to be modified by GSK-3. The crystal structure of human GSK$3 \beta$ provides a model for the binding of prephosphorylated substrates to the kinase (PDB ID are 1I09 [22] and 1H8F [21]). According to it, primed Ser/Thr is recognized by a positively charged binding pocket formed by residues Arg96, Arg180, and Lys205 that facilitates the binding of the phosphate group of primed substrates.

Some "priming kinases" have been identified, such as cdk-5 [55-57], PAR-1 [58], casein kinase I [59], PK-C [60], or PK-A [57]. However, it is not clear so far whether a second set of "nonprimed" substrates may define a different group of functions [61]. In addition, different glycogen synthase kinase-3 isoforms appear to exhibit distinct substrate preference in the brain [62].

3.4. Regulation by Subcellular Localization. In developmental brain, the presence of GSK-3 was high at E18 and peaked on P8, decreasing after that period [63]. In addition, this report showed that the developmental profile of GSK- $3 \alpha$ and GSK- $3 \beta$ is different, having $\beta$ downregulated after birth which suggested a differential role in neuronal development. However, the putative differential role of each isoform has been explored in few reports, that is, [7]. It is important to indicate that a portion of GSK-3, mostly $\beta$, has been reported to be associated in the growth cone. This GSK-3 pool appears to respond rapidly, being modified by phosphorylation and/or relocated in the growth cone by external signals such as Semaphorins [64] or NGF [65].

GSK-3 activity is also dependent on its subcellular localization; some data illustrated the presence of GSK-3 $\alpha$ and $\beta$ in many neuronal compartments and in primary neurons, either in axon, dendrite, or in nucleus $[66,67]$. In addition, GSK-3 has been found in the cytoplasm, nucleus and the mitochondria [18]. Considering the list of GSK3 substrates reported, it is evident that most of its activity should occur in the cytoplasm and in the nucleus, while we have less information about GSK-3 potential targets in the mitochondria. Recent data suggested that proteins such as Mcl-1 [68] and hexokinase [69] may be regulated by GSK3 activity. It has been suggested that nuclear GSK-3 may be involved in phosphorylation of many transcription factors such as cyclin D1, $\beta$-catenin, HSF-1, NFAT, and cAMPresponse element-binding protein, among others (Table 1 ), for review see $[28,70,71]$. Also, it has been proposed that GSK-3 in the nucleus may have a role in alternative splicing [72]. In addition, proapoptotic stimuli induce nuclear accumulation of GSK-3 $\beta$ [73]; however, this hypothesis has been not established in other neuronal death paradigms (D. Simon, unpublished observations).

Further insight into GSK-3 regulation has been gained very recently by revealing an essential role of multivesicular endosomes in the Wnt signalling pathway. A combination of protease protection assays, detergent permeabilization, and cryoimmunoelectron microscopy demonstrated that Wnt activation of the Frizzled and LRP6 receptors triggers sequestration of GSK-3 into these membrane-bounded organelles, leading to decreased GSK-3 levels in the cytosol [74]. This process seems to require $\beta$-catenin, forming a feed-forward loop by facilitating GSK-3 sequestration.

3.5. Regulation by Proteolytic Cleavage. A new mechanism of GSK-3 regulation has been recently proposed. This regulation involves the removal by calpain of a fragment from the N-terminal region of GSK-3, including the regulatory serines $9 / 21$. After removal of that fragment, GSK-3 becomes activated [75]. The same study showed that both isoforms $\alpha$ and $\beta$ are cleaved by calpain, although with different susceptibility. Moreover, GSK-3 truncation has been observed in human and mouse postmortem brain tissue [76]. It is noteworthy to consider that a similar mechanism has been described for $\beta$-catenin in hippocampal neurons, where after NMDA-receptor-dependent activation, calpain induced the cleavage of $\beta$-catenin at the $\mathrm{N}$ terminus, generating stable and truncated forms which maintain its transcriptional capacity [77]. Likewise, GSK-3 truncation is mediated by extracellular calcium and can be inhibited by memantine [76], an NMDA antagonist used for the treatment of Alzheimer's disease. Interestingly, GSK- $3 \beta$ has also been recently shown to be cleaved at the $\mathrm{N}$-terminus (and subsequently activated) by matrix metalloproteinase-2 (MMP-2) in cardiomyoblasts [78].

\section{Pathways Controlling GSK-3 Activity in Neurons}

The regulation of GSK-3, as previously mentioned, is an essential regulatory key controlling many physiological processes in neurons. Many external signals may trigger pathways that finally may activate or inhibit GSK-3 activity, either transiently or in more sustained way. These "physiological pathways" could be subdivided in two major clusters, those that essentially have to inhibit GSK-3 activity, and second, those that may, at least transiently, trigger GSK-3 activity. 
4.1. Inhibitory Pathways. Among these pathways, the signalling triggered by Insulin or IGF-1 $[19,79,80]$ and NGF/BDNF/NT3 $[81,82]$ has similar features. These tyrosine kinase receptors initiated cytoplasm signals in which the inhibition of GSK-3 activity is a common feature. It is generally accepted that the kinase implicated in this inhibition is $\mathrm{PKB} / \mathrm{Akt}$ [29-31], even though kinases such as PKA or ILK have also been implicated $[32,33]$. In all cases, phosphorylation on serine 21 and 9 ( $\alpha$ and $\beta$, resp.) represents the inhibition of the GSK3 kinase activity, as previously mentioned.

The second well-documented pathway is Wnt/Wingless signalling $[83,84]$. This signalling has been widely studied, and it has been shown to be essential in early embryonic patterning, cell fate, cellular polarity, and cell movement in both vertebrates and invertebrates [47, 85]. In many if not all cell systems, the canonical Wnt pathway is formed by a set of phylogenetically conserved proteins including the Wnt receptor frizzled $(f z)$, and a coreceptor LRP5/6; Dishevelled $(D s h)$, and a scaffolding protein that activates a complex formed by Axin/APC/GSK3- $\beta / \beta$-catenin [47, 85-88].

In this pathway, in the absence of ligand, GSK- $3 \beta$ phosphorylates $\beta$-catenin, among other proteins, this phosphorylation constituting part of a degradation signal for $\beta$-catenin. However, in the presence of Wnt, the receptor complex triggers a signal in which Dsh inhibits the activity of GSK$3 \beta$ by a mechanism not completely understood, so far. This system appears to be specific for GSK-3 $\beta$ as no counterpart has been described for GSK- $3 \alpha$ to date; however, some GSK3 activity appears to be necessary for Wnt signalling $[89,90]$. More recently, a bioinformatics-based screen for proteins whose stability may be controlled by GSK-3 [91] has led to the identification of a number of multiple Wnt signalling target proteins, suggesting that this pathway controls a broad range of cellular activities apart form $\beta$-cateninmediated transcriptional activation. Furthermore, GSK-3mediated Wnt signalling seems to regulate the turnover of many cellular proteins $[74,91]$, indicating that GSK3 phosphorylation-dependent protein degradation may be a widespread cellular mechanism to regulate a variety of cellular processes in response to extracellular signals [71].

Functional segregation of the insulin/growth factor and Wnt roles requires either that there be no exchange between the subsets of the cellular GSK- $3 \beta$ pool committed to each role, or that the recruitment of GSK-3 $\beta$ to the axin-APC complex can reverse or override inhibitory Ser9 phosphorylation present in a recruited GSK- $3 \beta$ molecule. Phosphatases capable of removing extant Ser9 phosphorylation are certainly known to be associated with the axinAPC complex $[92,93]$. Alternatively, the very substantial enhancement in activity towards $\beta$-catenin afforded by the axin "scaffolding" may simply allow a primed $\beta$-catenin substrate to outcompete a pSer9-GSK-3 $\beta \mathrm{N}$-terminal peptide for access to the substrate-binding site [26].

Estrogens regulate many physiological processes and fulfil a wide range of functions during development and differentiation in mammals of both sexes. The actions of estrogens are mediated by estrogen receptors and have been classified as either "genomic actions" or "nongenomic, rapid actions." The genomic actions are based on the capacity of the estrogen receptors (ERs) to modulate transcriptional activity either directly or through coactivators or corepressors, that is, $[94,95]$.

More recently, it has been shown that in addition to its direct transcriptional activity, estrogen receptors activate a set of cytoplasm signals in a similar manner to some growth factors. Hence, it has been reported that estradiol acts synergistically with IGF-1 in the brain or in neurons, activating the PI3K/Akt pathway [34, 96, 97]. We described that the addition of estradiol increases the serine phosphorylation of GSK-3. This inhibitory phosphorylation is timeand concentration dependent, and an antagonist of estradiol prevents this event. The kinase responsible is sensitive to the inhibition of the PI3K pathway, and for this reason, it seems that the best candidate would be Akt $[98,99]$. A more detailed analysis of these new signals will give us clear evidence whether this pathway is completely convergent with those using PI3K/Akt/GSK3, as previously mentioned.

4.2. Activation Pathways. In neurons, LPA has been shown to induce neurite retraction and the rounding up of neuroblastoma cell lines [100]. In some primary neurons, it also promotes growth cone collapse and neurite retraction $[37,101]$. This bioactive lipid acts as a growth factor through specific seven transmembrane domain receptors, denoted as lpa 1-4 [102, 103]. We described that GSK3 activity was increased after LPA treatment in diverse neuronal cells of different species in correlation with the neurite retraction process $[104,105]$. This activation correlated with an increase in GSK3-PTyr and may be downstream $\mathrm{G} \alpha_{12}$ or $G \alpha_{13}[101,105,106]$. The previous inhibition of GSK3 activity prevents, at least in part, the growth cone collapse response. Similarly, it has been reported that three different GSK-3 antagonists (LiCl, SB-216763, and SB-415286) can inhibit the growth cone collapse response induced by Sema $3 \mathrm{~A}[64]$.

However, the exact mechanism of how this activation of GSK3 occurs is not known, so far. Many reports indicate that in Dictyostelium discoideum GSK-3 activity may increase in response to cAMP binding to a heptahelical G-proteincoupled receptor. In this system, a tyrosine kinase and a tyrosine phosphatase have been described as regulators of GSK-3 activity [14, 40], but similar kinase and phosphatase have not been found in mammals.

Furthermore, it has been reported that Reelin and Netrin increased GSK-3 activity, similar to what LPA did. This Netrin or Reelin-dependent GSK-3 activation seems not to be a particular characteristic of the cell line or neuron used but rather a more general physiological process [107109]. Indeed, even in situations where the final balance is an inhibition of GSK-3 kinase activity, such as following the addition of IGF1/Insulin or after estradiol addition, a transient activation of GSK-3 could be observed [34, 38]. All these data suggest that the upregulation and downregulation of this kinase is more complex than might initially have been considered. 


\section{Pathological Activation of GSK-3}

Deregulation of GSK-3 has been linked to a wide range of human pathological conditions including type II diabetes, muscle wasting, cancer and neurological disorders such as bipolar disorder, schizophrenia, depression, stroke, sleep disorders, and Alzheimer's disease (AD), among others, for a review see [110].

Lithium and valproic acid are mood stabilizers widely used in the chronic treatment of bipolar disorders. Lithium ions directly inhibit GSK-3 [111], most likely by competing with magnesium [112], while valproic acid is able to inhibit GSK-3 activity in relevant therapeutic concentrations in human neuroblastoma cells [113] although in vivo direct inhibition of GSK-3 by valproic acid remains a matter of debate [114]. The precise mechanism of action by which lithium exerts its therapeutic effects is not known, but it is conceivable that the acute effects on GSK-3 result in changes in gene regulation and cellular changes which could affect the neuronal plasticity over time [115]. Actually, lithium is also an inhibitor of several phosphomonoesterases [116] and phosphoglucomutases [117], but the fact that GSK-3 has been shown to be significantly inhibited at therapeutic lithium concentrations [118-120] suggests that at least a significant proportion of lithium's therapeutic actions in bipolar disorder results from the inhibition of GSK-3, underlying its importance as a therapeutic target for this disorder $[121,122]$.

Lymphocytes of patients with schizophrenia show impaired GSK-3 protein levels and activity [123], whereas GSK-3 has been reported to be reduced in the frontal cortex of postmortem schizophrenic brains [124]. Since the Wnt family of genes plays a central role in normal brain development, it is possible that GSK-3 impairment may lead to abnormal neuronal development. More recently, a direct association has been shown between GSK-3 and the $\mathrm{N}$-terminal region of disrupted-in-schizophrenia-1 (DISC1), a strong genetic risk factor associated with schizophrenia [125]. Moreover, mounting evidence suggests that GSK-3 is a crucial node that mediates various cellular processes that are controlled by multiple signalling molecules such as DISC-1, PAR3, PAR6, and Wnt proteins that regulate neurodevelopment [88].

Interestingly, increased levels of GSK-3 have also been reported in postmortem analysis of brains from $\mathrm{AD}$ patients compared to age-matched control samples [126], whereas a spatial and temporal pattern of increased active GSK$3 \beta$ expression correlates with the progression of NFT and neurodegeneration [127]. Apart from being the major kinase to phosphorylate tau both in vitro and in vivo [128], GSK-3 has been recently proposed as the link between the two major histopathological hallmarks of AD, the extracellular amyloid plaques and the intracellular NFT $[129,130]$.

Exposure of primary neuronal cultures to $\mathrm{A} \beta$ induces activation of GSK-3 [131], tau phosphorylation [132], and cell death $[133,134]$, whereas blockade of GSK-3 expression by antisense oligonucleotides or its activity by lithium inhibits $\mathrm{A} \beta$-induced toxicity $[135,136]$. GSK-3 inhibition per se decreases $\mathrm{A} \beta$ production in cells and in an animal model of amyloidosis $[61,120]$, most likely through a mechanism involving inhibition of $\gamma$-secretase [137]. Furthermore, amyloid precursor protein (APP) itself is a substrate for GSK-3 in vitro and in vivo [138]. Finally, modulation of the GSK-3 signalling pathway by chronic lithium treatment of transgenic animals might also have neuroprotective effects by regulating APP maturation and processing [138].

In tauopathies such as frontotemporal dementia with Parkinsonism (FTDP) linked to chromosome 17, the presence of some mutations in tau protein correlates with the onset of the disease $[139,140]$. Treatment of transgenic mice overexpressing mutant human tau (P301L, 4RON), with the GSK-3 inhibitor lithium, has been shown to significantly decrease the levels of tau phosphorylation and significantly reduce the levels of aggregated, insoluble tau. Administration in this model of a second GSK-3 inhibitor, AR-A014418, also correlated with reduced insoluble tau levels, supporting the notion that lithium exerts its effect through GSK-3 inhibition [23]. More recently, chronic lithium administration has also been shown to reduce tau phosphorylation in the $3 \times \mathrm{Tg}-\mathrm{AD}$ mice [141], but did not significantly alter the amyloid load.

An increase in GSK-3 activity has also been shown to coincide with cell death following middle cerebral artery occlusion in mice which results in cortical infarcts [142], and a reduction in infarct volume with the GSK-3 inhibitor lithium was demonstrated [143], indicating that GSK-3 inhibition may be beneficial in stroke. In fact, pharmacological inhibition of GSK-3 reduced infarct volume and improved behaviour in a focal cerebral ischemia model [144].

\section{GSK-3 as a Therapeutic Target}

Besides deregulation of its activity in neurodegenerative processes, mounting evidence further suggests a potential role for GSK-3 as a therapeutic target in a range or other pathologies, including pancreatic cancer [145], parenchymal renal diseases [146], and HIV-1-associated dementia [147], among others.

The recent discovery that glycogen synthase kinase- 3 (GSK-3) promotes inflammation through nuclear factor kappa $\mathrm{B}(\mathrm{NF} \kappa \mathrm{B})$ has revealed new functions on regulating inflammatory processes [148]. Furthermore, GSK-3 inhibition provides protection from inflammatory conditions in different animal model [149], suggesting that GSK-3 inhibitors may have multiple effects influencing these conditions.

Finally, recent developments suggest an active role of GSK-3 $\beta$ in various human cancers, although its role in tumourigenesis and cancer progression remains controversial. It may function as a "tumour suppressor" for certain types of tumours, whereas it seems to promote growth and development for some others. Deregulation of GSK$3 \beta$ has been shown to promote gastrointestinal, pancreatic, and liver cancers and glioblastomas. Furthermore, GSK-3 $\beta$ inhibition attenuates cell survival and proliferation, induces cell senescence and apoptosis, and sensitizes tumour cells to chemotherapeutic agents [150] and ionizing radiation [151]. Nevertheless, an attractive target for a variety of human 
diseases, its therapeutic potential on tumourigenesis, and cancer chemotherapy still needs to be carefully evaluated [152].

The close involvement of GSK-3 activity in different human pathologies has sparked intense efforts in developing inhibitors as therapeutic agents. Thus, the discovery of small molecule GSK-3 inhibitors in the last few years has not only attracted significant attention to the protein as a therapeutic target but also has provided a means to further understand the physiological functions of GSK-3 and to gain further insight into the molecular basis of those disorders.

In fact, at least one small molecule GSK-3 inhibitor program has made it to the clinic [153]. Tideglusib (NP12) is a synthetic small molecule form the TDZD chemical class [110] which is currently in phase II development for two CNS indications: Alzheimer's disease and progressive supranuclear palsy (PSP), a tauopathy [154].

\section{Conclusion}

Three decades after its discovery as a protein kinase involved in glycogen metabolism, GSK-3 was revealed as a key enzyme in regulating many critical cellular processes, providing a link between many different substrates and various signalling pathways as well as gene expression. Modulation of its activity has also turned out to be much more complex than originally thought, as evident from what has been reviewed here. Furthermore, its role in a variety of highly relevant human pathological conditions has drawn significant attention to this enzyme as a potential therapeutic target, and the recent development of specific inhibitors has granted us new tools to dissect out its molecular and physiological functions while providing novel therapeutic agents. Taken all together, the next few years will certainly bring us further insights into the cellular functions of this fascinating enzyme.

\section{Acknowledgments}

The authors are grateful to Dr. J. Diaz-Nido, Dr. JJ Garrido, and Dra . I Anton, for corrections to the paper and thoughtful discussions; and Dra. D. Simon for providing some GSK3 schemes. This work was supported by grants from CDTI's program "CENIT-INGENIO 2010": "Consorcio MELIUS" (2006-2010), and "Consorcio MIND" (2006-2010), Ref050106090004. In addition, FW was supported by Grants from CIBERNED (which was an initiative of ISCIII), "Plan Nacional,” DGCYT, SAF2009-12249-C02-01, EU-FP7-2009CT222887 and by an Institutional grant from the "Fundación Areces." M. Medina acknowledges grant support from EUFP7 (NeuroGSK3, Project no. 223276) and from CDTI's CENIT program (DENDRIA, Project no. CEN-20101023).

\section{References}

[1] D. B. Rylatt, A. Aitken, T. Bilham, G. D. Condon, N. Embi, and P. Cohen, "Glycogen synthase from rabbit skeletal muscle. Amino acid sequence at the sites phosphorylated by glycogen synthase kinase-3, and extension of the Nterminal sequence containing the site phosphorylated by phosphorylase kinase," European Journal of Biochemistry, vol. 107, no. 2, pp. 529-537, 1980.

[2] D. M. Ferkey and D. Kimelman, "Glycogen synthase kinase$3 \beta$ mutagenesis identifies a common binding domain for GBP and axin," Journal of Biological Chemistry, vol. 277, no. 18, pp. 16147-16152, 2002.

[3] D. R. Alessi, F. B. Caudwell, M. Andjelkovic, B. A. Hemmings, and P. Cohen, "Molecular basis for the substrate specificity of protein kinase B; comparison with MAPKAP kinase-1 and p70 S6 kinase," FEBS Letters, vol. 399, no. 3, pp. 333-338, 1996.

[4] D. P. Hanger, K. Hughes, J. R. Woodgett, J. P. Brion, and B. H. Anderton, "Glycogen synthase kinase-3 induces Alzheimer's disease-like phosphorylation of tau: generation of paired helical filament epitopes and neuronal localisation of the kinase," Neuroscience Letters, vol. 147, no. 1, pp. 58-62, 1992.

[5] P. Cohen, "The Croonian Lecture 1998. Identification of a protein kinase cascade of major importance in insulin signal transduction," Philosophical Transactions of the Royal Society $B$, vol. 354, no. 1382, pp. 485-495, 1999.

[6] M. J. Hart, R. De Los Santos, I. N. Albert, B. Rubinfeld, and P. Polakis, "Downregulation of $\beta$-catenin by human Axin and its association with the APC tumor suppressor, $\beta$-catenin and GSK3 3," Current Biology, vol. 8, no. 10, pp. 573-581, 1998.

[7] J. J. Garrido, D. Simón, O. Varea, and F. Wandosell, "GSK3 alpha and GSK3 beta are necessary for axon formation," FEBS Letters, vol. 581, no. 8, pp. 1579-1586, 2007.

[8] F. R. Lucas and P. C. Salinas, "WNT-7a induces axonal remodeling and increases synapsin I levels in cerebellar neurons," Developmental Biology, vol. 192, no. 1, pp. 31-44, 1997.

[9] M. Pap and G. M. Cooper, "Role of glycogen synthase kinase3 in the phosphatidylinositol 3- kinase/Akt cell survival pathway," Journal of Biological Chemistry, vol. 273, no. 32, pp. 19929-19932, 1998.

[10] J. J. Lucas, F. Hernández, P. Gómez-Ramos, M. A. Morán, R. Hen, and J. Avila, "Decreased nuclear $\beta$-catenin, tau hyperphosphorylation and neurodegeneration in GSK-3 $\beta$ conditional transgenic mice," EMBO Journal, vol. 20, no. 1-2, pp. 27-39, 2001.

[11] K. Ishiguro, A. Shiratsuchi, S. Sato et al., "Glycogen synthase kinase $3 \beta$ is identical to tau protein kinase I generating several epitopes of paired helical filaments," FEBS Letters, vol. 325, no. 3, pp. 167-172, 1993.

[12] S. Lovestone, C. H. Reynolds, D. Latimer et al., "Alzheimer's disease-like phosphorylation of the microtubule-associated protein tau by glycogen synthase kinase-3 in transfected mammalian cells," Current Biology, vol. 4, no. 12, pp. 10771086, 1994.

[13] M. Pérez, A. I. Rojo, F. Wandosell, J. Díaz-Nido, and J. Avila, "Prion peptide induces neuronal cell death through a pathway involving glycogen synthase kinase 3," Biochemical Journal, vol. 372, no. 1, pp. 129-136, 2003.

[14] L. Kim, J. Liu, and A. R. Kimmel, "The novel tyrosine kinase ZAK1 activates GSK3 to direct cell fate specification," Cell, vol. 99, no. 4, pp. 399-408, 1999.

[15] K. Itoh, T. L. Tang, B. G. Neel, and S. Y. Sokol, "Specific modulation of ectodermal cell fates in Xenopus embryos by glycogen synthase kinase," Development, vol. 121, no. 12, pp. 3979-3988, 1995.

[16] L. Ruel, M. Bourouis, P. Heitzler, V. Pantesco, and P. Simpson, "Drosophila shaggy kinase and rat glycogen synthase kinase3 have conserved activities and act downstream of Notch," Nature, vol. 362, no. 6420, pp. 557-560, 1993. 
[17] S. Frame and P. Cohen, "GSK3 takes centre stage more than 20 years after its discovery," Biochemical Journal, vol. 359, no. 1 , pp. 1-16, 2001.

[18] C. A. Grimes and R. S. Jope, "The multifaceted roles of glycogen synthase kinase $3 \beta$ in cellular signaling," Progress in Neurobiology, vol. 65, no. 4, pp. 391-426, 2001.

[19] J. R. Woodgett, "Molecular cloning and expression of glycogen synthase kinase-3/Factor A," EMBO Journal, vol. 9, no. 8, pp. 2431-2438, 1990.

[20] F. Mukai, K. Ishiguro, Y. Sano, and S. C. Fujita, "Aternative splicing isoform of tau protein kinase I/glycogen synthase kinase $3 \beta$," Journal of Neurochemistry, vol. 81, no. 5, pp. 1073 1083, 2002.

[21] R. Dajani, E. Fraser, S. M. Roe et al., "Crystal structure of glycogen synthase kinase $3 \beta$ : structural basis for phosphateprimed substrate specificity and autoinhibition," Cell, vol. 105, no. 6, pp. 721-732, 2001.

[22] E. Ter Haar, J. T. Coll, D. A. Austen, H. M. Hsiao, L. Swenson, and J. Jain, "Structure of GSK3 $\beta$ reveals a primed phosphorylation mechanism," Nature Structural Biology, vol. 8, no. 7, pp. 593-596, 2001.

[23] W. Noble, E. Planel, C. Zehr et al., "Inhibition of glycogen synthase kinase- 3 by lithium correlates with reduced tauopathy and degeneration in vivo," Proceedings of the National Academy of Sciences of the United States of America, vol. 102, no. 19, pp. 6990-6995, 2005.

[24] J. Bain, L. Plater, M. Elliott et al., "The selectivity of protein kinase inhibitors: a further update," Biochemical Journal, vol. 408, no. 3, pp. 297-315, 2007.

[25] E. Fraser, N. Young, R. Dajani et al., "Identification of the Axin and Frat binding region of glycogen synthase kinase3," Journal of Biological Chemistry, vol. 277, no. 3, pp. 21762185, 2002.

[26] R. Dajani, E. Fraser, S. M. Roe et al., "Structural basis for recruitment of glycogen synthase kinase $3 \beta$ to the axin-APC scaffold complex," EMBO Journal, vol. 22, no. 3, pp. 494-501, 2003.

[27] Q. M. Wang, C. J. Fiol, A. A. DePaoli-Roach, and P. J. Roach, "Glycogen synthase kinase- $3 \beta$ is a dual specificity kinase differentially regulated by tyrosine and serine/threonine phosphorylation," Journal of Biological Chemistry, vol. 269, no. 20, pp. 14566-14574, 1994.

[28] A. J. Harwood, "Regulation of GSK-3: a cellular multiprocessor," Cell, vol. 105, no. 7, pp. 821-824, 2001.

[29] C. Sutherland, I. A. Leighton, and P. Cohen, "Inactivation of glycogen synthase kinase- $3 \beta$ by phosphorylation: new kinase connections in insulin and growth-factor signalling," Biochemical Journal, vol. 296, no. 1, pp. 15-19, 1993.

[30] V. Stambolic and J. R. Woodgett, "Mitogen inactivation of glycogen synthase kinase- $3 \beta$ in intact cells via serine 9 phosphorylation," Biochemical Journal, vol. 303, no. 3, pp. 701-704, 1994.

[31] S. Frame, P. Cohen, and R. M. Biondi, "A common phosphate binding site explains the unique substrate specificity of GSK3 and its inactivation by phosphorylation," Molecular Cell, vol. 7, no. 6, pp. 1321-1327, 2001.

[32] M. Delcommenne, C. Tan, V. Gray, L. Rue, J. Woodgett, and S. Dedhar, "Phosphoinositide-3-OH kinase-dependent regulation of glycogen synthase kinase 3 and protein kinase $\mathrm{B} / \mathrm{AKT}$ by the integrin-linked kinase," Proceedings of the National Academy of Sciences of the United States of America, vol. 95, no. 19, pp. 11211-11216, 1998.

[33] X. Fang, S. X. Yu, Y. Lu, R. C. Bast, J. R. Woodgett, and G. B. Mills, "Phosphorylation and inactivation of glycogen synthase kinase 3 by protein kinase A," Proceedings of the National Academy of Sciences of the United States of America, vol. 97, no. 22, pp. 11960-11965, 2000.

[34] P. Cardona-Gomez, M. Perez, J. Avila, L. M. Garcia-Segura, and F. Wandosell, "Estradiol inhibits GSK3 and regulates interaction of estrogen receptors, GSK3, and beta-catenin in the hippocampus," Molecular and Cellular Neuroscience, vol. 25, no. 3, pp. 363-373, 2004.

[35] Q. Ding, W. Xia, J. C. Liu et al., "Erk associates with and primes GSK- $3 \beta$ for its inactivation resulting in upregulation of $\beta$-catenin," Molecular Cell, vol. 19, no. 2, pp. 159-170, 2005.

[36] T. M. Thornton, G. Pedraza-Alva, B. Deng et al., "Phosphorylation by $\mathrm{p} 38$ MAPK as an alternative pathway for GSK3 $\beta$ inactivation," Science, vol. 320, no. 5876, pp. 667-670, 2008.

[37] C. L. Sayas, M. T. Moreno-Flores, J. Avila, and F. Wandosell, "The neurite retraction induced by lysophosphatidic acid increases Alzheimer's disease-like Tau phosphorylation," Journal of Biological Chemistry, vol. 274, no. 52, pp. 3704637052, 1999.

[38] M. Lesort, R. S. Jope, and G. V. W. Johnson, "Insulin transiently increases tau phosphorylation: involvement of glycogen synthase kinase- $3 \beta$ and Fyn tyrosine kinase," Journal of Neurochemistry, vol. 72, no. 2, pp. 576-584, 1999.

[39] J. A. Hartigan, W. C. Xiong, and G. V. W. Johnson, "Glycogen synthase kinase $3 \beta$ is tyrosine phosphorylated by PYK2," Biochemical and Biophysical Research Communications, vol. 284, no. 2, pp. 485-489, 2001.

[40] L. Kim, A. Harwood, and A. R. Kimmel, "Receptordependent and tyrosine phosphatase-mediated inhibition of GSK3 regulates cell fate choice," Developmental Cell, vol. 3, no. 4, pp. 523-532, 2002.

[41] A. Cole, S. Frame, and P. Cohen, "Further evidence that the tyrosine phosphorylation of glycogen synthase kinase3 (GSK3) in mammalian cells is an autophosphorylation event," Biochemical Journal, vol. 377, no. 1, pp. 249-255, 2004.

[42] P. Cohen and M. Goedert, "GSK3 inhibitors: development and therapeutic potential," Nature Reviews Drug Discovery, vol. 3, no. 6, pp. 479-487, 2004.

[43] I. Buch, D. Fishelovitch, N. London, B. Raveh, H. J. Wolfson, and R. Nussinov, "Allosteric regulation of glycogen synthase kinase $3 \beta$ : a theoretical study," Biochemistry, vol. 49 , no. 51, pp. 10890-10901, 2010.

[44] D. Simón, M. J. Benitez, A. Gimenez-Cassina et al., "Pharmacological inhibition of GSK-3 is not strictly correlated with a decrease in tyrosine phosphorylation of residues 216/279," Journal of Neuroscience Research, vol. 86, no. 3, pp. 668-674, 2008.

[45] J. R. Muñoz-Montaño, F. J. Moreno, J. Avila, and J. DíazNido, "Lithium inhibits Alzheimer's disease-like tau protein phosphorylation in neurons," FEBS Letters, vol. 411, no. 2-3, pp. 183-188, 1997.

[46] A. Takashima, T. Honda, K. Yasutake et al., "Activation of tau protein kinase I/glycogen synthase kinase- $3 \beta$ by amyloid $\beta$ peptide (25-35) enhances phosphorylation of tau in hippocampal neurons," Neuroscience Research, vol. 31, no. 4, pp. 317-323, 1998.

[47] R. T. Moon, A. D. Kohn, G. V. De Ferrari, and A. Kaykas, "WNT and $\beta$-catenin signalling: diseases and therapies," Nature Reviews Genetics, vol. 5, no. 9, pp. 691-701, 2004.

[48] H. Aberle, A. Bauer, J. Stappert, A. Kispert, and R. Kemler, " $\beta$-catenin is a target for the ubiquitin-proteasome pathway," EMBO Journal, vol. 16, no. 13, pp. 3797-3804, 1997. 
[49] Z. Castaño, P. R. Gordon-Weeks, and R. M. Kypta, "The neuron-specific isoform of glycogen synthase kinase- $3 \beta$ is required for axon growth," Journal of Neurochemistry, vol. 113, no. 1, pp. 117-130, 2010.

[50] L. Li, H. Yuan, C. D. Weaver et al., "Axin and Frat1 interact with Dvl and GSK, bridging Dvl to GSK in Wnt-mediated regulation of LEF-1," EMBO Journal, vol. 18, no. 15, pp. 4233-4240, 1999.

[51] C. Yost, G. H. Farr, S. B. Pierce, D. M. Ferkey, M. M. Chen, and D. Kimelman, "GBP, an inhibitor of GSK-3, is implicated in Xenopus development and oncogenesis," Cell, vol. 93, no. 6, pp. 1031-1041, 1998.

[52] W. H. Stoothoff, J.-H. Cho, R. P. McDonald, and G. V.W. Johnson, "FRAT-2 preferentially increases glycogen synthase kinase $3 \beta$-mediated phosphorylation of primed sites, which results in enhanced tau phosphorylation," Journal of Biological Chemistry, vol. 280, no. 1, pp. 270-276, 2005.

[53] R. Van Amerongen, M. Nawijn, J. Franca-Koh et al., "Frat is dispensable for canonical Wnt signaling in mammals," Genes and Development, vol. 19, no. 4, pp. 425-430, 2005.

[54] H. Y. Chou, S. L. Howng, T. S. Cheng et al., "GSKIP is homologous to the axin GSK3 $\beta$ interaction domain and functions as a negative regulator of GSK $3 \beta$," Biochemistry, vol. 45, no. 38, pp. 11379-11389, 2006.

[55] A. D. C. Alonso, B. Li, I. Grundke-Iqbal, and K. Iqbal, "Polymerization of hyperphosphorylated tau into filaments eliminates its inhibitory activity," Proceedings of the National Academy of Sciences of the United States of America, vol. 103, no. 23, pp. 8864-8869, 2006.

[56] W. Noble, V. Olm, K. Takata et al., "Cdk5 is a key factor in tau aggregation and tangle formation in vivo," Neuron, vol. 38, no. 4, pp. 555-565, 2003.

[57] A. Sengupta, Q. Wu, I. Grundke-Iqbal, K. Iqbal, and T. J. Singh, "Potentiation of GSK-3-catalyzed Alzheimer-like phosphorylation of human tau by cdk5," Molecular and Cellular Biochemistry, vol. 167, no. 1-2, pp. 99-105, 1997.

[58] I. Nishimura, Y. Yang, and B. Lu, "PAR-1 kinase plays an initiator role in a temporally ordered phosphorylation process that confers tau toxicity in Drosophila," Cell, vol. 116, no. 5, pp. 671-682, 2004.

[59] S. Amit, A. Hatzubai, Y. Birman et al., "Axin-mediated CKI phosphorylation of $\beta$-catenin at Ser 45: a molecular switch for the Wnt pathway," Genes and Development, vol. 16, no. 9, pp. 1066-1076, 2002.

[60] S. J. Liu, A. H. Zhang, H. L. Li et al., "Overactivation of glycogen synthase kinase-3 by inhibition of phosphoinositol3 kinase and protein kinase $\mathrm{C}$ leads to hyperphosphorylation of tau and impairment of spatial memory," Journal of Neurochemistry, vol. 87, no. 6, pp. 1333-1344, 2003.

[61] C. Twomey and J. V. McCarthy, "Presenilin-1 is an unprimed glycogen synthase kinase- $3 \beta$ substrate," FEBS Letters, vol. 580, no. 17, pp. 4015-4020, 2006.

[62] M. P. M. Soutar, W.-Y. Kim, R. Williamson et al., "Evidence that glycogen synthase kinase-3 isoforms have distinct substrate preference in the brain," Journal of Neurochemistry, vol. 115, no. 4, pp. 974-983, 2010.

[63] M. Takahashi, K. Tomizawa, R. Kato et al., "Localization and developmental changes of $\tau$ protein kinase I/glycogen synthase kinase- $3 \beta$ in rat brain," Journal of Neurochemistry, vol. 63, no. 1, pp. 245-255, 1994.

[64] B. J. Eickholt, F. S. Walsh, and P. Doherty, "An inactive pool of GSK-3 at the leading edge of growth cones is implicated in Semaphorin 3A signaling," Journal of Cell Biology, vol. 157, no. 2, pp. 211-217, 2002.
[65] F. Q. Zhou, J. Zhou, S. Dedhar, Y. H. Wu, and W. D. Snider, "NGF-induced axon growth is mediated by localized inactivation of GSK-3 $\beta$ and functions of the microtubule plus end binding protein APC," Neuron, vol. 42, no. 6, pp. 897-912, 2004.

[66] P. Watcharasit, G. N. Bijur, J. W. Zmijewski et al., "Direct, activating interaction between glycogen synthase kinase- $3 \beta$ and p53 after DNA damage," Proceedings of the National Academy of Sciences of the United States of America, vol. 99, no. 12, pp. 7951-7955, 2002.

[67] G. N. Bijur and R. S. Jope, "Glycogen synthase kinase-3 beta is highly activated in nuclei and mitochondria," Neuroreport, vol. 14, no. 18, pp. 2415-2419, 2003.

[68] C. Morel, S. M. Carlson, F. M. White, and R. J. Davis, "Mcl-1 integrates the opposing actions of signaling pathways that mediate survival and apoptosis," Molecular and Cellular Biology, vol. 29, no. 14, pp. 3845-3852, 2009.

[69] A. Gimenez-Cassina, F. Lim, T. Cerrato, G. M. Palomo, and J. Diaz-Nido, "Mitochondrial hexokinase II promotes neuronal survival and acts downstream of glycogen synthase kinase3," Journal of Biological Chemistry, vol. 284, no. 5, pp. 30013011, 2009.

[70] P. Cohen and S. Frame, “The renaissance of GSK3," Nature Reviews Molecular Cell Biology, vol. 2, no. 10, pp. 769-776, 2001.

[71] C. Xu, N. G. Kim, and B. M. Gumbiner, "Regulation of protein stability by GSK3 mediated phosphorylation," Cell Cycle, vol. 8, no. 24, pp. 4032-4039, 2009.

[72] J. Avila, J. J. Lucas, M. Pérez, and F. Hernández, "Role of tau protein in both physiological and pathological conditions," Physiological Reviews, vol. 84, no. 2, pp. 361-384, 2004.

[73] G. N. Bijur and R. S. Jope, "Proapoptotic stimuli induce nuclear accumulation of glycogen synthase kinase-3 beta," Journal of Biological Chemistry, vol. 276, no. 40, pp. 3743637442, 2001.

[74] V. F. Taelman, R. Dobrowolski, J.-L. Plouhinec et al., "Wnt signaling requires sequestration of Glycogen Synthase Kinase 3 inside multivesicular endosomes," Cell, vol. 143, no. 7, pp. 1136-1148, 2010.

[75] P. Goñi-Oliver, J. J. Lucas, J. Avila, and F. Hernández, "Nterminal cleavage of GSK-3 by calpain: a new form of GSK-3 regulation," Journal of Biological Chemistry, vol. 282, no. 31, pp. 22406-22413, 2007.

[76] P. Goñi-Oliver, J. Avila, and F. Hernández, "Calpainmediated truncation of GSK-3 in post-mortem brain samples," Journal of Neuroscience Research, vol. 87, no. 5, pp. 1156-1161, 2009.

[77] K. Abe and M. Takeichi, "NMDA-receptor activation induces calpain-mediated beta-catenin cleavages for triggering gene expression," Neuron, vol. 53, no. 3, pp. 387-397, 2007.

[78] A. D. Kandasamy and R. Schulz, "Glycogen synthase kinase$3 \beta$ is activated by matrix metalloproteinase- 2 mediated proteolysis in cardiomyoblasts," Cardiovascular Research, vol. 83, no. 4, pp. 698-706, 2009.

[79] P. Cohen, "The coordinated control of metabolic pathways by broad-specificity protein kinases and phosphatases," Current Topics in Cellular Regulation, vol. 27, pp. 23-37, 1985.

[80] D. A. E. Cross, D. R. Alessi, P. Cohen, M. Andjelkovich, and B. A. Hemmings, "Inhibition of glycogen synthase kinase-3 by insulin mediated by protein kinase B," Nature, vol. 378, no. 6559, pp. 785-789, 1995.

[81] R. J. Crowder and R. S. Freeman, "Glycogen synthase kinase$3 \beta$ activity is critical for neuronal death caused by inhibiting phosphatidylinositol 3-kinase or Akt but not for death caused 
by nerve growth factor withdrawal," Journal of Biological Chemistry, vol. 275, no. 44, pp. 34266-34271, 2000.

[82] L. Mai, R. S. Jope, and X. Li, "BDNF-mediated signal transduction is modulated by GSK $3 \beta$ and mood stabilizing agents," Journal of Neurochemistry, vol. 82, no. 1, pp. 75-83, 2002.

[83] X. He, J.-P. Saint-Jeanneti, J. R. Woodgett, H. E. Varmas, and I. B. Dawld, "Glycogen synthase kinase-3 and dorsoventral patterning in Xenopus embryos," Nature, vol. 374, no. 6523, pp. 617-622, 1995.

[84] E. Siegfried, T. B. Chou, and N. Perrimon, "Wingless signaling acts through zeste-white 3, the Drosophila homolog of glycogen synthase kinase-3, to regulate engrailed and establish cell fate," Cell, vol. 71, no. 7, pp. 1167-1179, 1992.

[85] P. C. Salinas, "Signaling at the vertebrate synapse: new roles for embryonic morphogens?" Journal of Neurobiology, vol. 64, no. 4, pp. 435-445, 2005.

[86] X. He, M. Semenov, K. Tamai, and X. Zeng, "LDL receptorrelated proteins 5 and 6 in Wnt/ $\beta$-catenin signaling: arrows point the way," Development, vol. 131, no. 8, pp. 1663-1677, 2004.

[87] R. van Amerongen and R. Nusse, "Towards an integrated view of Wnt signaling in development," Development, vol. 136, no. 19, pp. 3205-3214, 2009.

[88] E. M. Hur and F. Q. Zhou, "GSK3 signalling in neural development," Nature Reviews Neuroscience, vol. 11, pp. 539$551,2010$.

[89] X. Zeng, K. Tamai, B. Doble et al., "A dual-kinase mechanism for Wnt co-receptor phosphorylation and activation," Nature, vol. 438, no. 7069, pp. 873-877, 2005.

[90] C. Niehrs and J. Shen, "Regulation of Lrp6 phosphorylation," Cellular and Molecular Life Sciences, vol. 67, pp. 2551-2562, 2010.

[91] N. G. Kim, C. Xu, and B. M. Gumbiner, "Identification of targets of the Wnt pathway destruction complex in addition to $\beta$-catenin," Proceedings of the National Academy of Sciences of the United States of America, vol. 106, no. 13, pp. 51655170, 2009.

[92] W. Hsu, L. Zeng, and F. Costantini, "Identification of a domain of axin that binds to the serine/threonine protein phosphatase 2A and a self-binding domain," Journal of Biological Chemistry, vol. 274, no. 6, pp. 3439-3445, 1999.

[93] J. M. Seeling, J. R. Miller, R. Gil, R. T. Moon, R. White, and D. M. Virshup, "Regulation of $\beta$-catenin signaling by the B56 subunit of protein phosphatase 2A," Science, vol. 283, no. 5410, pp. 2089-2091, 1999.

[94] M. Beato and J. Klug, "Steroid hormone receptors: an update," Human Reproduction Update, vol. 6, no. 3, pp. 225236, 2000.

[95] M. Beato and A. Sánchez-Pacheco, "Interaction of steroid hormone receptors with the transcription initiation complex," Endocrine Reviews, vol. 17, no. 6, pp. 587-609, 1996.

[96] P. Mendez, I. Azcoitia, and L. M. Garcia-Segura, "Interdependence of oestrogen and insulin-like growth factor-I in the brain: potential for analysing neuroprotective mechanisms," Journal of Endocrinology, vol. 185, no. 1, pp. 11-17, 2005.

[97] P. Mendez, I. N. Azcoitia, and L. M. Garcia-Segura, "Estrogen receptor alpha forms estrogen-dependent multimolecular complexes with insulin-like growth factor receptor and phosphatidylinositol 3-kinase in the adult rat brain," Molecular Brain Research, vol. 112, no. 1-2, pp. 170-176, 2003.

[98] O. Varea, J. J. Garrido, A. Dopazo, P. Mendez, L. M. GarciaSegura, and F. Wandosell, "Estradiol activates $\beta$-catenin dependent transcription in neurons," PLoS ONE, vol. 4, no. 4, Article ID e5153, 2009.
[99] O. Varea, M. A. Arevalo, J. J. Garrido, L. M. Garcia-Segura, F. Wandosell, and P. Mendez, "Interaction of estrogen receptors with insulin-like growth factor-I and Wnt signaling in the nervous system," Steroids, vol. 75, no. 8-9, pp. 565-569, 2010.

[100] G. Tigyi, D. J. Fischer, A. Sebök, F. Marshall, D. L. Dyer, and R. Miledi, "Lysophosphatidic acid-induced neurite retraction in PC12 cells: neurite-protective effects of cyclic AMP signaling," Journal of Neurochemistry, vol. 66, no. 2, pp. 549558, 1996.

[101] O. Kranenburg, M. Poland, F. P. G. Van Horck, D. Drechsel, A. Hall, and W. H. Moolenaar, "Activation of RhoA by lysophosphatidic acid and $\mathrm{G} \alpha(12 / 13)$ subunits in neuronal cells: induction of neurite retraction," Molecular Biology of the Cell, vol. 10, no. 6, pp. 1851-1857, 1999.

[102] J. Chun, E. J. Goetzl, T. Hla et al., "International Union of Pharmacology. XXXIV. Lysophospholipid receptor nomenclature," Pharmacological Reviews, vol. 54, no. 2, pp. 265-269, 2002.

[103] M. E. Lin, D. R. Herr, and J. Chun, "Lysophosphatidic acid (LPA) receptors: signaling properties and disease relevance," Prostaglandins and Other Lipid Mediators, vol. 91, no. 3-4, pp. 130-138, 2010.

[104] C. L. Sayas, M. T. Moreno-Flores, J. Avila, and F. Wandosell, "The neurite retraction induced by lysophosphatidic acid increases Alzheimer's disease-like Tau phosphorylation," Journal of Biological Chemistry, vol. 274, no. 52, pp. 3704637052, 1999.

[105] C. L. Sayas, J. Avila, and F. Wandosell, "Glycogen synthase kinase- 3 is activated in neuronal cells by $\mathrm{G} \alpha 12$ and $\mathrm{G} \alpha 13$ by Rho-independent and Rho-dependent mechanisms," Journal of Neuroscience, vol. 22, no. 16, pp. 6863-6875, 2002.

[106] C. L. Sayas, J. Ávila, and F. Wandosell, "Regulation of neuronal cytoskeleton by lysophosphatidic acid: role of GSK3," Biochimica et Biophysica Acta, vol. 1582, no. 1-3, pp. 144153, 2002.

[107] U. Beffert, G. Morfini, H. H. Bock, H. Reyna, S. T. Brady, and J. Herz, "Reelin-mediated signaling locally regulates protein kinase B/Akt and glycogen synthase kinase $3 \beta$," Journal of Biological Chemistry, vol. 277, no. 51, pp. 49958-49964, 2002.

[108] J. A. Del Río, C. González-Billault, J. M. Ureña et al., “MAP1B is required for netrin 1 signaling in neuronal migration and axonal guidance," Current Biology, vol. 14, no. 10, pp. 840850, 2004.

[109] C. González-Billault, J. A. Del Río, J. M. Ureña et al., “A role of MAP1B in reelin-dependent neuronal migration," Cerebral Cortex, vol. 15, no. 8, pp. 1134-1145, 2005.

[110] A. Martínez, A. Castro, and M. Medina, Glycogen Synthase Kinase 3 (GSK-3) and Its Inhibitors-Drug discovery and Development, Wiley Series, Drug Discovery and Development, John Wiley \& Sons, New York, NY, USA, 2006.

[111] P. S. Klein and D. A. Melton, "A molecular mechanism for the effect of lithium on development," Proceedings of the National Academy of Sciences of the United States of America, vol. 93, no. 16, pp. 8455-8459, 1996.

[112] Y. Li-Smerin, E. S. Levitan, and J. W. Johnson, "Free intracellular $\mathrm{Mg}$ concentration and inhibition of NMDA responses in cultured rat neurons," Journal of Physiology, vol. 533, no. 3, pp. 729-743, 2001.

[113] G. Chen, L. D. Huang, Y. M. Jiang, and H. K. Manji, "The mood-stabilizing agent valproate inhibits the activity of glycogen synthase kinase-3," Journal of Neurochemistry, vol. 72, no. 3, pp. 1327-1330, 1999. 
[114] G. Rosenberg, "The mechanisms of action of valproate in neuropsychiatric disorders: can we see the forest for the trees?" Cellular and Molecular Life Sciences, vol. 64, no. 16, pp. 2090-2103, 2007.

[115] R. S. Jope, "Anti-bipolar therapy: mechanism of action of lithium," Molecular Psychiatry, vol. 4, no. 2, pp. 117-128, 1999.

[116] J. D. York, J. W. Ponder, and P. W. Majerus, "Definition of a metal-dependent/Li(+)-inhibited phosphomonoesterase protein family based upon a conserved three-dimensional core structure," Proceedings of the National Academy of Sciences of the United States of America, vol. 92, no. 11, pp. 5149-5153, 1995.

[117] W. J. Ray, E. S. Szymanki, and L. Ng, "The binding of lithium and of anionic metabolites to phosphoglucomutase," Biochimica et Biophysica Acta, vol. 522, no. 2, pp. 434-442, 1978.

[118] A. Shaldubina, G. Agam, and R. H. Belmaker, "The mechanism of lithium action: state of the art, ten years later," Progress in Neuro-Psychopharmacology and Biological Psychiatry, vol. 25, no. 4, pp. 855-866, 2001.

[119] T. D. Gould and H. K. Manji, "Signaling networks in the pathophysiology and treatment of mood disorders," Journal of Psychosomatic Research, vol. 53, no. 2, pp. 687-697, 2002.

[120] C. J. Phiel, C. A. Wilson, V. M. Y. Lee, and P. S. Klein, "GSK$3 \alpha$ regulates production of Alzheimer's disease amyloid- $\beta$ peptides," Nature, vol. 423, no. 6938, pp. 435-439, 2003.

[121] X. Li, G. N. Bijur, and R. S. Jope, "Glycogen synthase kinase- $3 \beta$, mood stabilizers, and neuroprotection," Bipolar Disorders, vol. 4, no. 2, pp. 137-144, 2002.

[122] M. K. Rowe, C. Wiest, and D. M. Chuang, "GSK-3 is a viable potential target for therapeutic intervention in bipolar disorder," Neuroscience and Biobehavioral Reviews, vol. 31, no. 6, pp. 920-931, 2007.

[123] S. D. Yang, J. S. Yu, T. T. Lee, C. C. Yang, M. H. Ni, and Y. Y. Yang, "Dysfunction of protein kinase FA/GSK-3 $\alpha$ in lymphocytes of patients with schizophrenic disorder," Journal of Cellular Biochemistry, vol. 59, no. 1, pp. 108-116, 1995.

[124] N. Kozlovsky, R. H. Belmaker, and G. Agam, "Low GSK$3 \beta$ immunoreactivity in postmortem frontal cortex of schizophrenic patients," American Journal of Psychiatry, vol. 157, no. 5, pp. 831-833, 2000.

[125] T. V. Lipina, O. Kaidanovich-Beilin, S. Patel et al., "Genetic and pharmacological evidence for schizophrenia-related Disc1 interaction with GSK-3," Synapse, vol. 65, no. 3, pp. 234-248, 2011.

[126] J. J. Pei, T. Tanaka, Y. C. Tung, E. Braak, K. Iqbal, and I. Grundke-Iqbal, "Distribution, levels, and activity of glycogen synthase kinase-3 in the Alzheimer disease brain," Journal of Neuropathology and Experimental Neurology, vol. 56, no. 1, pp. 70-78, 1997.

[127] K. Leroy, A. Boutajangout, M. Authelet, J. R. Woodgett, B. H. Anderton, and J. P. Brion, "The active form of glycogen synthase kinase- $3 \beta$ is associated with granulovacuolar degeneration in neurons in Alzheimers's disease," Acta Neuropathologica, vol. 103, no. 2, pp. 91-99, 2002.

[128] M. Medina and J. Avila, "Glycogen synthase kinase-3 (GSK3) inhibitors for the treatment of Alzheimer's disease," Current Pharmaceutical Design, vol. 16, no. 25, pp. 27902798, 2010.

[129] C. Hooper, R. Killick, and S. Lovestone, "The GSK3 hypothesis of Alzheimer's disease," Journal of Neurochemistry, vol. 104, no. 6, pp. 1433-1439, 2008.
[130] D. Muyllaert, A. Kremer, T. Jaworski et al., "Glycogen synthase kinase-3 $\beta$, or a link between amyloid and tau pathology?" Genes, Brain and Behavior, vol. 7, supplement 1, pp. 57-66, 2008.

[131] A. Takashima, K. Noguchi, G. Michel et al., "Exposure of rat hippocampal neurons to amyloid $\beta$ peptide (25-35) induces the inactivation of phosphatidyl inositol-3 kinase and the activation of tau protein kinase I/glycogen synthase kinase3ß," Neuroscience Letters, vol. 203, no. 1, pp. 33-36, 1996.

[132] A. Ferreira, Q. Lu, L. Orecchio, and K. S. Kosik, "Selective phosphorylation of adult tau isoforms in mature hippocampal neurons exposed to fibrillar a $\beta$," Molecular and Cellular Neurosciences, vol. 9, no. 3, pp. 220-234, 1997.

[133] A. Takashima, K. Noguchi, K. Sato, T. Hoshino, and K. Imahori, "tau Protein kinase I is essential for amyloid $\beta$ protein-induced neurotoxicity," Proceedings of the National Academy of Sciences of the United States of America, vol. 90, no. 16, pp. 7789-7793, 1993.

[134] J. Busciglio, A. Lorenzo, J. Yeh, and B. A. Yankner, " $\beta$ Amyloid fibrils induce tau phosphorylation and loss of microtubule binding," Neuron, vol. 14, no. 4, pp. 879-888, 1995.

[135] M. Pérez, E. Ribe, A. Rubio et al., "Characterization of a double (amyloid precursor protein-tau) transgenic: tau phosphorylation and aggregation," Neuroscience, vol. 130, no. 2, pp. 339-347, 2005.

[136] E. M. Ribé, M. Pérez, B. Puig et al., "Accelerated amyloid deposition, neurofibrillary degeneration and neuronal loss in double mutant APP/tau transgenic mice," Neurobiology of Disease, vol. 20, no. 3, pp. 814-822, 2005.

[137] A. E. Aplin, G. M. Gibb, J. S. Jacobsen, J. M. Gallo, and B. H. Anderton, "In vitro phosphorylation of the cytoplasmic domain of the amyloid precursor protein by glycogen synthase kinase-3 $\beta$," Journal of Neurochemistry, vol. 67, no. 2, pp. 699-707, 1996.

[138] E. Rockenstein, M. Torrance, A. Adame et al., "Neuroprotective effects of regulators of the glycogen synthase kinase- $3 \beta$ signaling pathway in a transgenic model of Alzheimer's disease are associated with reduced amyloid precursor protein phosphorylation," Journal of Neuroscience, vol. 27, no. 8, pp. 1981-1991, 2007.

[139] F. Hernández and J. Avila, “Tauopathies," Cellular and Molecular Life Sciences, vol. 64, no. 17, pp. 2219-2233, 2007.

[140] M. Medina, "Recent developments in tau-based therapeutics for neurodegenerative diseases," Recent Patents on CNS Drug Discovery, vol. 6, no. 1, pp. 20-30, 2011.

[141] A. Caccamo, S. Oddo, L. X. Tran, and F. M. LaFerla, "Lithium reduces tau phosphorylation but not $\mathrm{A} \beta$ or working memory deficits in a transgenic model with both plaques and tangles," American Journal of Pathology, vol. 170, no. 5, pp. 1669-1675, 2007.

[142] R. V. Bhat, J. Shanley, M. P. Correll et al., "Regulation and localization of tyrosine phosphorylation of glycogen synthase kinase- $3 \beta$ in cellular and animal models of neuronal degeneration," Proceedings of the National Academy of Sciences of the United States of America, vol. 97, no. 20, pp. 11074-11079, 2000.

[143] S. Nonaka and D. M. Chuang, "Neuroprotective effects of chronic lithium on focal cerebral ischemia in rats," NeuroReport, vol. 9, no. 9, pp. 2081-2084, 1998.

[144] S. H. Koh, A. R. Yoo, D. I. Chang, S. J. Hwang, and S. H. Kim, "Inhibition of GSK-3 reduces infarct volume and improves neurobehavioral functions," Biochemical and 
Biophysical Research Communications, vol. 371, no. 4, pp. 894-899, 2008.

[145] G. Garcea, M. M. Manson, C. P. Neal et al., "Glycogen synthase kinase-3 beta; A new target in pancreatic cancer?" Current Cancer Drug Targets, vol. 7, no. 3, pp. 209-215, 2007.

[146] S. H. Obligado, O. Ibraghimov-Beskrovnaya, A. Zuk, L. Meijer, and P. J. Nelson, "CDK/GSK-3 inhibitors as therapeutic agents for parenchymal renal diseases," Kidney International, vol. 73, no. 6, pp. 684-690, 2008.

[147] S. Dewhurst, S. B. Maggirwar, G. Schifitto, H. E. Gendelman, and H. A. Gelbard, "Glycogen synthase kinase 3 beta (GSK-3 $\beta)$ as a therapeutic target in neuroAIDS," Journal of Neuroimmune Pharmacology, vol. 2, no. 1, pp. 93-96, 2007.

[148] L. Dugo, M. Collin, and C. Thiemermann, "Glycogen synthase kinase $3 \beta$ as a target for the therapy of shock and inflammation," Shock, vol. 27, no. 2, pp. 113-123, 2007.

[149] R. S. Jope, C. J. Yuskaitis, and E. Beurel, "Glycogen synthase kinase-3 (GSK3): inflammation, diseases, and therapeutics," Neurochemical Research, vol. 32, no. 4-5, pp. 577-595, 2007.

[150] K. Miyashita, M. Nakada, A. Shakoori et al., "An emerging strategy for cancer treatment targeting aberrant glycogen synthase kinase 3 $\beta$," Anti-Cancer Agents in Medicinal Chemistry, vol. 9, no. 10, pp. 1114-1122, 2009.

[151] D. K. Thotala, D. E. Hallahan, and E. M. Yazlovitskaya, "Inhibition of glycogen synthase kinase $3 \beta$ attenuates neurocognitive dysfunction resulting from cranial irradiation," Cancer Research, vol. 68, no. 14, pp. 5859-5868, 2008.

[152] R. Mishra, "Glycogen synthase kinase 3 beta: can it be a target for oral cancer," Molecular Cancer, vol. 9, p. 144, 2010.

[153] M. Medina and A. Castro, "Glycogen synthase kinase-3 (GSK-3) inhibitors reach the clinic," Current Opinion in Drug Discovery and Development, vol. 11, no. 4, pp. 533-543, 2008.

[154] T. del Ser, "Phase IIa clinical trial on Alzheimer's disease with NP12, a GSK-3 inhibitor," Alzheimers Dementia, vol. 6, p. S147, 2010. 


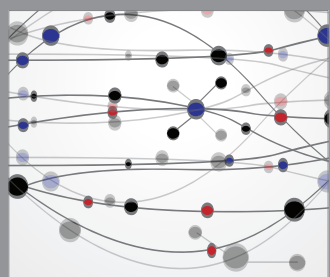

The Scientific World Journal
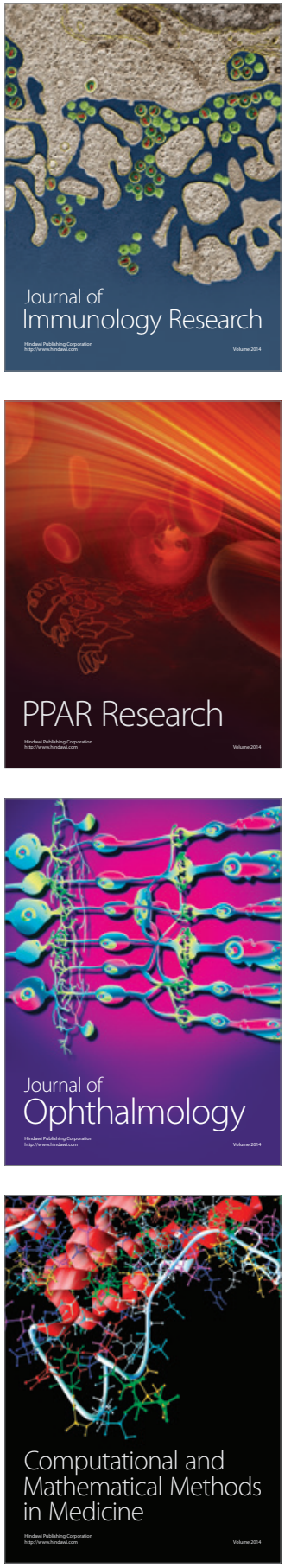

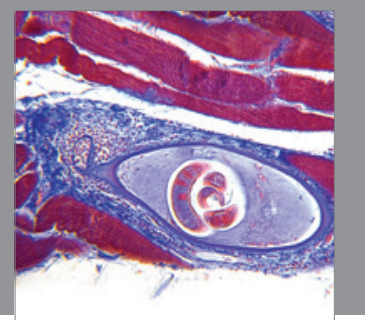

Gastroenterology

Research and Practice
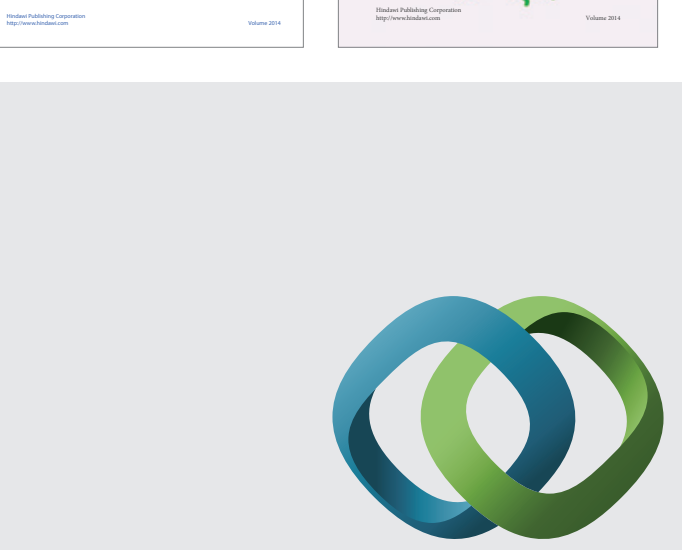

\section{Hindawi}

Submit your manuscripts at

http://www.hindawi.com
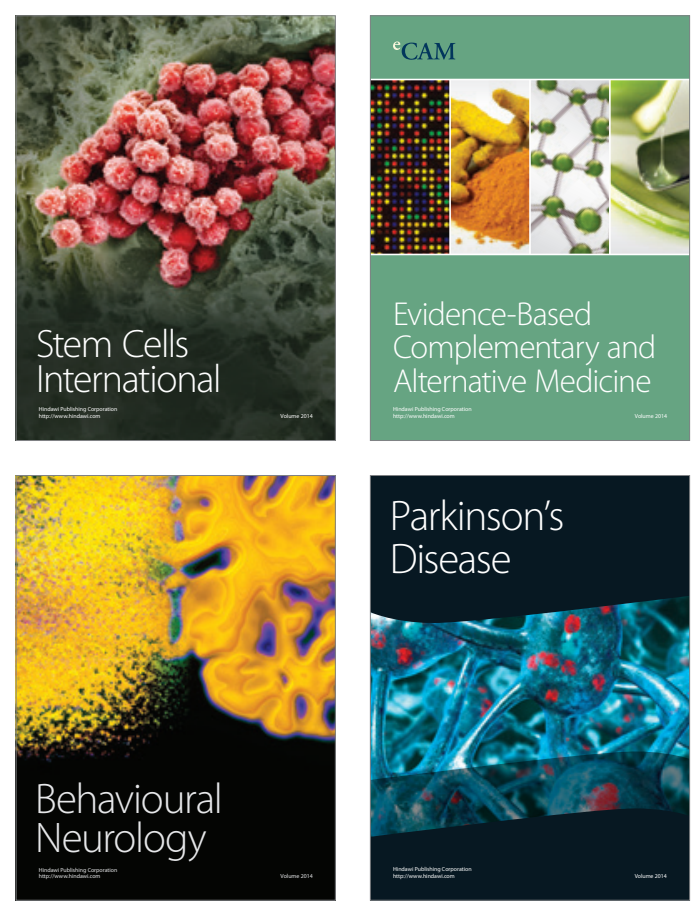

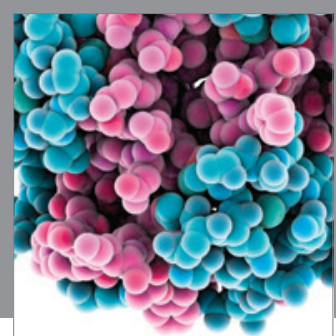

Journal of
Diabetes Research

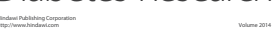

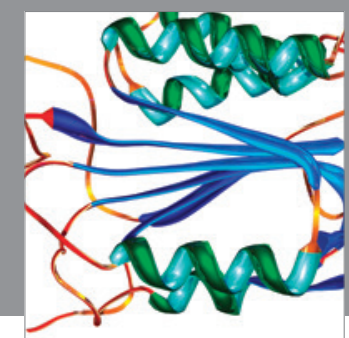

Disease Markers
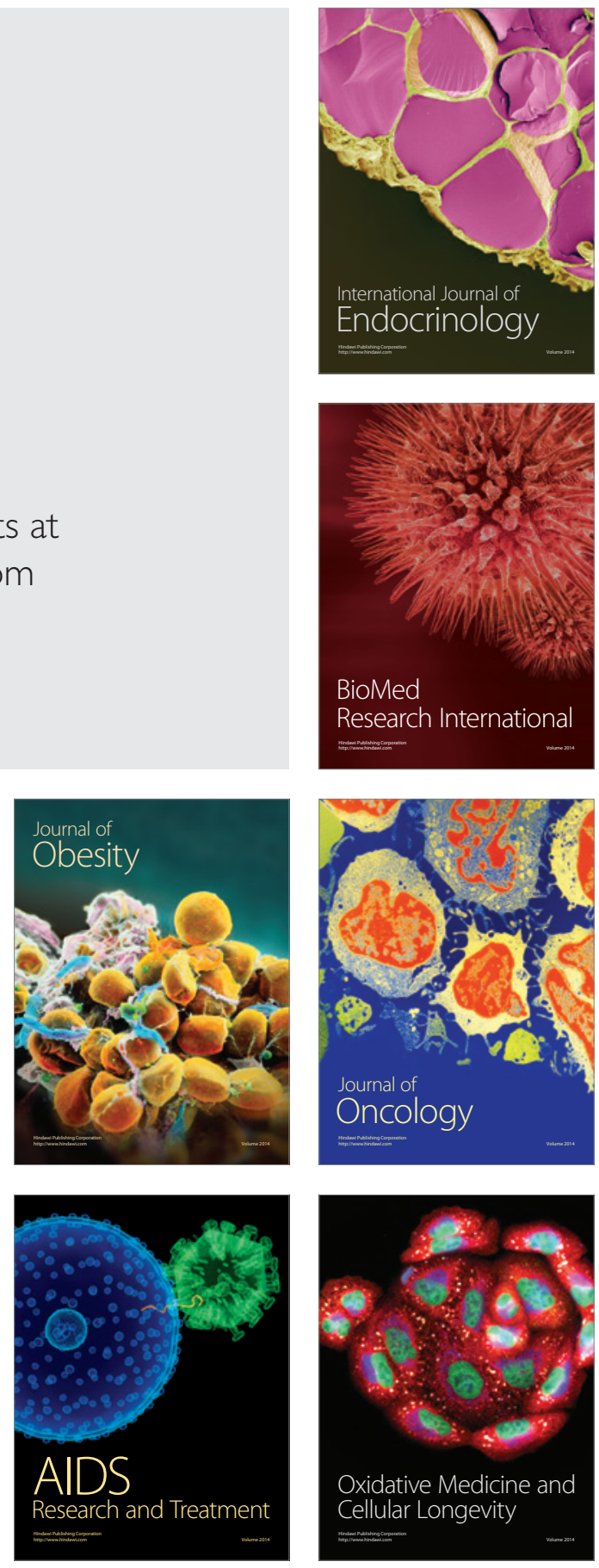